\title{
Oxygen saturation during the first 24 hours of life
}

\author{
L M O'Brien, V A Stebbens, C F Poets, E G Heycock, D P Southall
}

\begin{abstract}
Aim-To determine normative data for arterial oxygen saturation, measured by pulse oximetry $\left(\mathrm{SpO}_{2}\right)$, in healthy full term infants throughout their first 24 hours of life.

Methods-Long term recordings of $\mathrm{SpO}_{2}$, pulse waveform, and breathing movements were made on 90 infants. Recordings were analysed for baseline $\mathrm{SpO}_{2}$, episodes of desaturation $\left(\mathrm{SpO}_{2} \leqslant 80 \%\right)$, apnoeic pauses of $\geqslant$ four seconds, and periodic apnoea ( $\geqslant$ three apnoeic pauses, each separated by $\leqslant 19$ breaths).

Results-Median baseline $\mathrm{SpO}_{2}$ was $98.3 \%$ (range 88.7-100). Longitudinal analysis at four hour intervals showed that $\mathrm{SpO}_{2}$ remained stable until 20-24 hours of age, when it became significantly lower $(p<0.03)$. Episodic desaturations were identified in 23 recordings. Nine prolonged desaturations $\left(\mathrm{SpO}_{2} \leqslant 80 \%\right.$ for $\geqslant 20$ seconds) were identified in six recordings. Four desaturations fell to $\leqslant 60 \%$. Periodic apnoea was identified in $60 \%$ of recordings.

Conclusion-The range of $\mathrm{SpO}_{2}$ during the first 24 hours of life is similar to that found previously during the first month of life. The clinical significance of the prolonged episodes of desaturation observed justifies further investigation.
\end{abstract}

(Arch Dis Child Fetal Neonatal Ed 2000;83:F35-F38)

Keywords: pulse oximetry; neonate; oxygen saturation; apnoea

Pulse oximetry is widely used in clinical practice to obtain data on arterial oxygen saturation $\left(\mathrm{SpO}_{2}\right)$. It is a non-invasive technique which requires no calibration and is able to provide instantaneous data, which have been shown to correlate well with blood gas measurements. ${ }^{1-3}$

This department has published information on $\mathrm{SpO}_{2}$ in healthy full term infants from 2 days of life throughout the first ${ }^{4}$ and second ${ }^{5}$ months of life, during infancy, ${ }^{6}$ and the rest of childhood. ${ }^{7}$ No infants younger than 24 hours of age were included in these studies. Other investigators have obtained data on $\mathrm{SpO}_{2}$ from infants immediately after delivery. ${ }^{8-11}$ These measurements were, however, not continuous, which is unfortunate, as many cardiorespiratory changes occur during the first postnatal day. We therefore performed a study to establish oxygen saturation in healthy full term infants during their first 24 hours of life. To our knowledge, this study provides a continuum of information on $\mathrm{SpO}_{2}$ values not previously available for this age group.

\section{Subjects and methods}

Infants were recruited during the third trimester of pregnancy, from mothers booked to deliver at the North Staffordshire Maternity Hospital. Mothers were selected by a systematic sampling procedure, and informed parental consent was obtained during pregnancy. The study was approved by the local research ethics committee. Infants were only studied if they were born after 37 weeks of gestation and were apparently healthy upon delivery.

Recordings were made of arterial oxygen saturation as measured by pulse oximetry $\left(\mathrm{SpO}_{2}\right.$; Nellcor N200/Mallinckrodt, St Louis, Missouri, USA; modified to produce beat to beat measurements), pulse plethysmograph for validation of the $\mathrm{SpO}_{2}$ signal, and breathing movements from a pressure capsule (Graseby Medical, Watford, Herts, UK) taped to the abdominal wall. All monitor alarms were muted. These data were recorded on to portable computers (Apple Inc, Cupertino, CA, USA) and subsequently downloaded and printed on to paper using a thermal printer (Graphtec, Tokyo, Japan). The recordings were printed at $3.1 \mathrm{~mm} / \mathrm{s}$.

The printouts were analysed by an experienced research assistant without knowledge of the infants' ages at the time of the recordings. The analysis was performed in accordance with previously published studies. ${ }^{5}$ Briefly, analysis of baseline $\mathrm{SpO}_{2}$ values was restricted to periods of regular pattern breathing (RPB). Apnoeic pauses of $\geqslant$ four seconds were identified in RPB, non-regular pattern breathing (NRPB), and periodic apnoea (PA). These pauses were split into three groups according to their lengths: 4-7.9 seconds, 8-11.9 seconds, and $\geqslant 12$ seconds. We also identified pauses of $\geqslant 20$ seconds and looked at surrounding patterns.

PA, defined as the occurrence of $\geqslant$ three apnoeic pauses each separated by $\leqslant 19$ breaths, was identified. Apnoeas of $\leqslant 10$ seconds in duration are common in infancy. Pauses in breathing of $\geqslant$ four seconds were chosen to define an apnoeic episode in order to maintain comparability with previous studies. ${ }^{4-7}$ Other authors include pauses of breathing from $\geqslant$ two seconds, ${ }^{12} \geqslant$ five seconds, ${ }^{13-15}$ or $\geqslant$ six seconds in duration. ${ }^{16}$ Apnoea has arbitrarily been defined as prolonged if there is cessation of breathing for $\geqslant$ 20 seconds, or for a shorter period if it is associated with bradycardia, cyanosis, or pallor. ${ }^{17}$

Episodic desaturations $\left(\mathrm{SpO}_{2} \leqslant 80 \%\right)$ were identified and their duration recorded. Episodic desaturations that occurred within 12 seconds of the start of an apnoeic pause were also identified. ${ }^{5}$ 
Table 1 Recording results in the first 24 hours after delivery divided into six four hour stages

\begin{tabular}{|c|c|c|c|c|c|c|c|}
\hline & $0-4$ & $4-8$ & $8-12$ & $12-16$ & $16-20$ & $20-24$ & $0-24$ \\
\hline No of recordings & 85 & 85 & 86 & 82 & 74 & 68 & 90 \\
\hline Baseline $\mathrm{SpO}_{2}(\%)$ & $\begin{array}{l}99.0 \\
(88.4-100)\end{array}$ & $\begin{array}{l}98.4 \\
(87.6-100)\end{array}$ & $\begin{array}{l}98.6 \\
(78.1-100)\end{array}$ & $\begin{array}{l}98.1 \\
(79.6-100)\end{array}$ & $\begin{array}{l}98.3 \\
(81.2-100)\end{array}$ & $\begin{array}{l}97.8 \\
(83.3-100)\end{array}$ & $\begin{array}{l}98.3 \\
(88.7-100)\end{array}$ \\
\hline Recordings with desaturations (\%) & 8 & 11 & 8 & 11 & 11 & 4 & 26 \\
\hline Desaturations associated with a pause (\%) & 25 & 53 & 20 & 50 & 54 & 82 & 48 \\
\hline Apnoeic pauses associated with a desaturation (\%) & 3 & 9 & 2 & 10 & 7 & 9 & 40 \\
\hline Recordings containing periodic apnoea (\%) & 20 & 31 & 31 & 26 & 23 & 27 & 60 \\
\hline
\end{tabular}

Baseline $\mathrm{SpO}_{2}$ values given as median (range).

After overall measurement, the data were assigned to age intervals to allow sequential analysis; there were therefore six intervals each representing a four hour stage. These intervals represented the postnatal age of the infant. Variables were calculated for each age interval. Results are presented as medians and ranges. Statistical significance was assessed using the Mann-Whitney U test.

\section{Results}

Ninety infants were successfully studied (49 boys). Of these, 71 were born by unassisted vaginal delivery, nine by assisted delivery, and 10 by caesarean section (four emergency). Eight infants received bag and mask resuscitation at delivery.

The median age at the commencement of recordings was one hour, and the median duration of recordings was 21.5 hours (range 4.5-23.4). The median duration of RPB was 3.5 hours (range 0.75-6.5). Median baseline $\mathrm{SpO}_{2}$, as measured during $\mathrm{RPB}$, was $98.3 \%$ (range 88.7-100). Analysis by intervals of four hours showed that median $\mathrm{SpO}_{2}$ was significantly ( $p<0.03$ ) lower during the $20-24$ hour interval than any other age interval. Although $\mathrm{SpO}_{2}$ was at its highest value during the first four hours after delivery, this was not significantly different (table 1 ).

$\mathrm{SpO}_{2}$ levels in recordings of infants who received bag and mask resuscitation were significantly lower during the 24 hour period $(\mathrm{p}<0.03)$, compared with the other recordings. When analysed in intervals of four hours, $\mathrm{SpO}_{2}$ was found to be significantly lower in these infants during the first eight hours of life $(p<0.05)$ and also at $20-24$ hours of age $(\mathrm{p}=0.006)$.

Seven recordings were excluded from analysis of episodic desaturation. These had low overall baseline $\mathrm{SpO}_{2}$ values (median 91.5\%) and saturation was $\leqslant 80 \%$ in a proportion of their regular breathing episodes; the lowest $\mathrm{SpO}_{2}$ value within an episode of $\mathrm{RPB}$ had a median value of $81.2 \%$ (range $78.1-88.6$ ). Signal at $\leqslant 80 \%$ in these episodes did not therefore represent episodic desaturation. If included, it would have inflated the values for the variable artificially, and would have misrepresented the clinical state of these infants; although they had a low baseline saturation, they were not necessarily experiencing falls within it. None of these seven infants exhibited falls in $\mathrm{SpO}_{2}$ of $\leqslant 60 \%$. This subgroup of infants included five who were distressed (two received bag and mask resuscitation) and two who were delivered by caesarean section; only one of the seven infants had an unremarkable delivery.

Eighty three desaturations were observed in $23(26 \%)$ recordings. The median number of desaturations, corrected to the median duration of signal (21.5 hours), was 0 (range $0-17.4$ ), with the 90th centile at 4.1. Forty three $(52 \%)$ of these desaturations occurred without relation to an apnoeic pause; the median duration of these desaturations was 9.3 seconds (range 0.5-286.8). This compared with a median of 0.8 seconds (range $0.3-89.6$ ) in desaturations associated with an apnoeic pause. The longest desaturation observed was therefore 4.8 minutes; for much of this time (4.0 minutes) the $\mathrm{SpO}_{2}$ was $\leqslant 60 \%$. In addition to the measured artefact free desaturation, there were four brief periods of movement artefact when the infant was probably attempting to improve respiratory function (fig 1). There was no associated apnoeic pause, and this was the only desaturation identified during the recording of this infant. Clinical cyanosis was not reported.

Prolonged desaturations $\left(\mathrm{SpO}_{2} \leqslant 80 \%\right.$ for $\geqslant 20$ seconds) were identified in six recordings. There were nine such desaturations, the median duration being 41.6 seconds (range 20.8-286.8). Three of the latter desaturations showed falls in $\mathrm{SpO}_{2}$ to $\leqslant 60 \%$, as did one other shorter desaturation. The median duration of these desaturations to $\leqslant 60 \%$ was 14

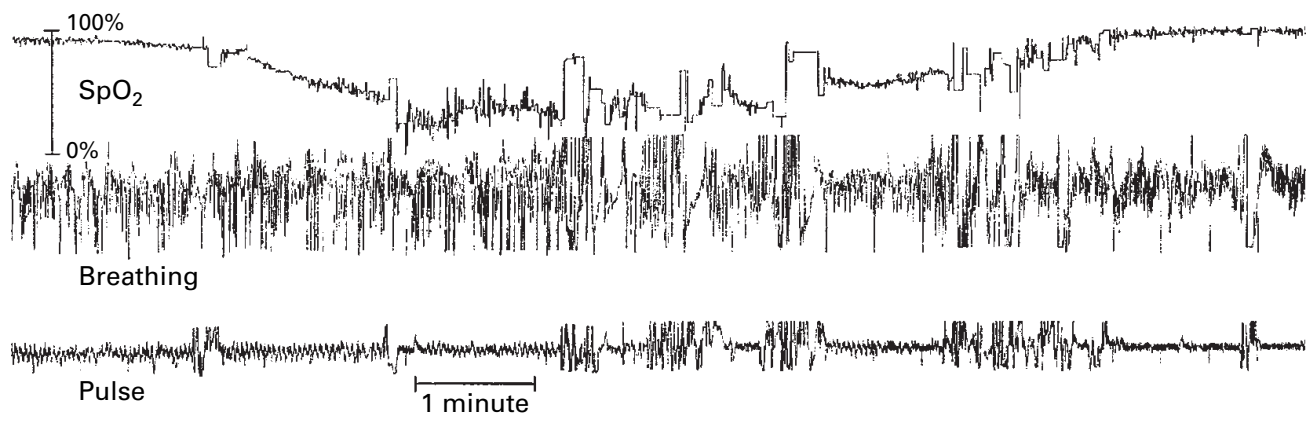

Figure 1 A severe and prolonged arterial oxygen desaturation. 
seconds (range 6.7-237.2). During all four of these desaturations, the infants were reported to have been feeding; none were reported to have become cyanotic. Three of the four episodic desaturations that exhibited falls in $\mathrm{SpO}_{2}$ to $\leqslant 60 \%$ occurred without association with an apnoeic pause.

Only one recording contained episodes of desaturation $(n=4)$ during $R P B$, and these all occurred immediately after apnoeic pauses. During NRPB, only $37 \%$ of episodic desaturations was associated with apnoeic pauses.

A minority of apnoeic pauses was associated with an episodic desaturation. In RPB there was a total of four apnoeic pauses $(0.3 \%$ of all pauses), which were associated with an episodic desaturation, compared with 25 apnoeic pauses $(0.3 \%)$ in non-regular breathing and 11 apnoeic pauses $(0.7 \%)$ in PA with such desaturations. Overall, only $0.4 \%$ of apnoeic pauses was associated with a desaturation. PA was the only breathing pattern to show desaturations associated with apnoeic pauses in the first four hours of life, although such pauses were only identified in one infant.

Nine infants showed 10 apnoeic pauses of $\geqslant 20$ seconds in duration, the longest of which was 26.9 seconds. Two of these apnoeas were identified in RPB, four in NRPB, and four in PA. Only one apnoea, the longest, was associated with a desaturation; this resulted in a fall in $\mathrm{SpO}_{2}$ to below $60 \%$ for 16 seconds. Of the infants who exhibited apnoeic pauses $\geqslant 20$ seconds, there were significantly $(p=0.03)$ more who received bag and mask resuscitation at delivery.

PA was identified in $60 \%$ of recordings. In these recordings the median duration was 3.4 minutes (range 0.4-93.9). There were no significant differences between the median durations of PA when analysis was performed across intervals of four hours. The median number of episodes of PA per recording was four (range 1-55); the longest episode of PA was 5.3 minutes.

\section{Discussion}

We have defined reference data for aspects of oxygen saturation in healthy full term infants during their first 24 hours of life. Median baseline $\mathrm{SpO}_{2}$ values were higher than those reported for the first week of life, ${ }^{4}$ and were relatively stable across the first 24 hours. The median value at $20-24$ hours of life $(97.8 \%)$ is similar to that previously reported for healthy full term infants between 2 and 7 days of age $(97.6 \%),{ }^{4}$ using similar experimental methods.

Lower $\mathrm{SpO}_{2}$ values in the period after bag and mask resuscitation at birth have not been reported previously. They are, perhaps, not surprising as the necessity to resuscitate an infant may reflect lower lung volumes after delivery and this may continue to be reflected in the significantly lower saturations measured during the first eight hours of life. A mismatching of ventilation and perfusion in areas of atelectasis can result in right to left shunting within the lung. The significantly lower values in $\mathrm{SpO}_{2}$ observed during the 20-24 hour age interval were unexpected and remain unexplained.

\section{Key messages}

- During the first day of life, healthy term infants have baseline $\mathrm{SpO}_{2}$ values that are very similar to those of older infants, with a range from $89-100 \%$

- Four healthy term infants each showed a severe oxygen desaturation; three of these events were not associated with an apnoeic pause

- Apnoeic pauses, experienced by most of these infants, are rarely associated with a fall in oxygen saturation to $\leqslant 80 \%$

- Nine infants had 10 apnoeic pauses of $\geqslant 20$ seconds, only one of which was associated with a fall in oxygen saturation to $\leqslant 80 \%$

Episodes of desaturation, during which $\mathrm{SpO}_{2}$ fell to $\leqslant 80 \%$, were relatively uncommon, with only $26 \%$ of recordings containing such episodes. Only $20 \%$ of recordings contained episodic desaturations $\geqslant$ four seconds in duration. The four infants who exhibited severe desaturations $\left(\mathrm{SpO}_{2} \leqslant 60 \%\right)$ were all reported to have been feeding, and these infants may have had difficulty coordinating breathing and feeding. ${ }^{18}{ }^{19}$ None of the previous studies that monitored $\mathrm{SpO}_{2}$ levels during the first postnatal day ${ }^{8-11}$ reported data on episodic desaturations.

The desaturations that occurred without association with an apnoeic pause were more frequent and of longer duration than those that occurred in relation to a pause. This may suggest that ventilation/perfusion mismatching or obstructive apnoea have a role to play, although airflow was not measured in this study so obstructive apnoea could not be identified. Hypoventilation may be a contributing factor in some desaturations, particularly as this has been observed in newborn infants during feeding. ${ }^{20}$ Our methodology does not enable quantitative analyses to be undertaken on the breathing pattern. Rapid depletion of small lung oxygen stores after an apnoeic pause ${ }^{21}$ may only partly explain the desaturations observed, particularly when the desaturation is severe, as the circulation time for blood in infants is rapid (five to nine seconds). ${ }^{22}$ The proportion of apnoeic pauses of $\geqslant$ four seconds associated with a desaturation $(0.4 \%)$ also suggests that apnoeas are not the only cause of desaturation during the first day of life.

Although there is a wealth of information describing pauses in breathing as "apnoeas" when the duration of the pause is between two and six seconds, ${ }^{4-7}{ }^{12-16}$ the clinician is more interested in apnoeas lasting $\geqslant 20$ seconds. Very few infants $(n=9)$ in this study exhibited this phenomenon, which is in accordance with other studies ${ }^{15} 1623$ performed within a few days of birth. However, three of the eight infants receiving bag and mask resuscitation had apnoeic pauses $\geqslant 20$ seconds. The significance of bag and mask resuscitation to prolonged apnoeic pauses is not clear, although the process of resuscitation may affect lung mechanics, 
particularly in infants who have never breathed and whose lungs still contain fluid.

Some previous studies have shown no evidence of PA before about 48 hours of age. ${ }^{24}{ }^{25}$ The present study is in agreement with that of Fenner et $a l^{26}$ in that PA was observed in full term infants less than 48 hours old. In contrast with the results of Fenner et al, who found PA in $41 \%$ of infants, the present study found PA to occur in most of the infants studied $(60 \%)$. Different definitions of PA may have contributed to the discrepancy between reports.

In conclusion, reference values for baseline $\mathrm{SpO}_{2}$ and its relation to breathing pattern have been obtained in 90 healthy full term infants throughout the first 24 hours of life. Baseline oxygenation was relatively stable during the first postnatal day, slightly higher than we have shown in healthy full term infants during their first month of life, but lower than in older infants. Episodic desaturations were apparent in $26 \%$ of infants studied, and several infants exhibited severe and prolonged episodes, most of which occurred without association with an apnoeic pause. The clinical significance of these episodes remains to be determined. PA has been identified in the breathing pattern of full term infants during their first day of life.

Our thanks go to the parents who allowed us to monitor their babies, the midwifery staff of the North Staffordshire Hospital, and Mrs Jackie Kelly who analysed the recordings. Thanks also to Mrs Fozia Hussain who assisted with the data collection. The recording/analysis equipment and consumables were provided recording/analysis equipment and consumables were provided by financial contributions from Babes in Arms, Cot Death Research, Little Ones, and the Sir Jules Thorn Trust. Mr Wilts, UK) and Dr Chris Hall (Bournemouth University, UK) Wilts, UK) and Dr Chris Hall (Bou
developed the recording systems.

1 Jennis MS, Peabody JL. Pulse oximetry: an alternative method for the assessment of oxygenation in newborn method for the assessment of
infants. Pediatrics 1987;79:524-8.

2 Southall DP, Bignall S, Stebbens VA, Alexander JR, Rivers RPA, Lissauer T. Pulse oximeter and transcutaneous arterial oxygen measurements in neonatal an

3 Mok J, Pintar M, Benson L, McLaughlin FJ, Levinson H. Evaluation of noninvasive measurements of oxygenation in stable infants. Crit Care Med 1986;14:960-3.

4 Poets CF, Stebbens VA, Lang JA, O'Brien LM, Boon AW, Southall DP. Arterial oxygen saturation in healthy term neonates. Eur F Pediatr 1996;155:219-23.

5 Stebbens VA, Poets CF, Alexander JR, Arrowsmith WA, Southall DP. Oxygen saturation and breathing patterns in infancy. 1. Full term infants in the second month of life. Arch Dis Child 1991;66:569-73.

6 Poets CF, Stebbens VA, Southall DP. Arterial oxygen saturation and breathing movements during the first year of life. Fournal of Developmental Physiology 1991;15:341-5.
7 Poets CF, Stebbens VA, Samuels MP, Southall DP. Oxygen saturation and breathing patterns in children. Pediatrics 1993;92:686-90.

8 Harris AP, Sendak MJ, Donham RT. Changes in arterial oxygen saturation immediately after birth in the human neonate. F Pediatr 1986;109:117-19.

9 House JT, Schultetus RR, Gravenstein N. Continuous neonatal evaluation in the delivery room by pulse oximetry. $\mathcal{F}$ Clin Monit 1987;3:96-100.

10 Porter KB, Goldhamer R, Mankad A, Peevy K, Gaddy J, Spinnato JA. Evaluation of arterial oxygen saturation in pregnant patients and their newborns. Obstet Gynecol 1988;71:354-7.

11 Dimich I, Singh PP, Adell A, Hendler M, Sonnenklar N, Jhaveri M. Evaluation of oxygen saturation monitoring by pulse oximetry in neonates in the delivery system. Can $\mathcal{F}$ Anaesth 1991;38:985-8.

12 Flores-Guevara R, Plonin P, Curzi-Dascalova L, et al. Sleep apneas in normal neonates and infants during the first 3 months of life. Neuropediatrics 1982;13(suppl):21-8.

13 Flores-Guevara R, Lacombe J, Monod B, Bernhard N, Guidasci S, Monod N. Polysomnograms and cardiopneumo grams in SIDS research. Biol Neonate 1986;49:270-6.

14 Flores-Guevara R, Sternberg B, Peirano P, Guidasci S, Durupt N, Monod N. Respiratory pauses and periodic breathing assessed by cardio-pneumography in normal infants and in SIDS siblings. Neuropediatrics 1986;17:5962.

15 Stein IM, White A, Kennedy JL, Merisalo RL, Chernoff H, Gould JB. Apnea recordings of healthy infants at 40,44 and 52 weeks postconception. Pediatrics 1979;63:724-30.

16 Hoppenbrouwers T, Hodgman JE, Harper RM, Hofmann E, Sterman MB, McGinty DJ. Polygraphic studies of normal infants during the first six months of life. III. Incidence of apnea and periodic breathing. Pediatrics 1977;60:418-25.

17 Task Force on Prolonged Apnea. American Academy of Pediatrics. Prolonged Apnea. Pediatrics 1978;61:651-2.

18 Durand M, Leahy FN, MacCallum M, Cates DB, Rigatto $\mathrm{H}$, Chernick V. Effect of feeding on the chemical control of breathing in the newborn infant. Pediatr Res 1981;15:1509-12.

19 Bamford O, Taciak V, Gewolb IH. The relationship between rhythmic swallowing and breathing during suckle feeding in term neonates. Pediatr Res 1992;31:619-24.

20 Mathew OP, Clark ML, Pronske ML, Luna-Solarzano HG, Peterson MD. Breathing pattern and ventilation during oral feeding in term newborn infants. $f$ Pediatr 1985;106:810-13.

21 Henderson-Smart DJ, Read DJC. Reduced lung volume during behavioral active sleep in the newborn. $f$ Appl Physiol 1979;46:1081-5.

22 Poets CF, Samuels MP, Southall DP. Potential role of intrapulmonary shunting in the genesis of hypoxemic episodes in infants and young children. Pediatrics 1992;90:385-91.

23 Southall DP, Richards J, Brown DJ, Johnston PGB, de Swiet $\mathrm{M}$, Shinebourne EA. 24-hour tape recordings of ECG and respiration in the newborn infant with findings related to sudden death and unexplained brain damage in infancy. Arch Dis Child 1980;55:7-16.

24 Waite SP, Thoman EB. Periodic apnea in the full-term infant: individual consistency, sex differences, and state specificity. Pediatrics 1982;70:79-86.

25 Chernick V, Heldrich F, Avery ME. Periodic breathing of premature infants. F Pediatr 1964;64:330-40.

26 Fenner A, Schalk U, Hoenicke H, Wendenburg A, Roehling T. Periodic breathing in premature and neonatal babies: incidence, breathing pattern, respiratory gas tensions, response to changes in the composition of ambient air. Pediatr Res 1973;7:174-83. 